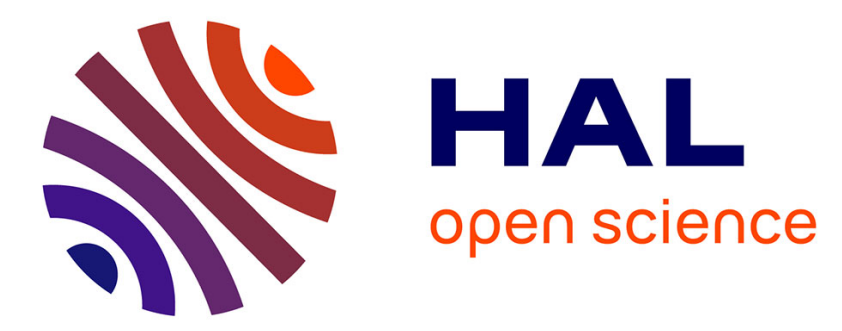

\title{
Wind turbine wake influence on the mixing of relative humidity quantified through wind tunnel experiments
}

\author{
Martin Obligado, Raúl Bayoán Cal, Christophe Brun
}

\section{To cite this version:}

Martin Obligado, Raúl Bayoán Cal, Christophe Brun. Wind turbine wake influence on the mixing of relative humidity quantified through wind tunnel experiments. Journal of Renewable and Sustainable Energy, 2021, 13 (2), pp.023308. 10.1063/5.0039090 . hal-03199149

\section{HAL Id: hal-03199149 \\ https://hal.univ-grenoble-alpes.fr/hal-03199149}

Submitted on 23 Sep 2021

HAL is a multi-disciplinary open access archive for the deposit and dissemination of scientific research documents, whether they are published or not. The documents may come from teaching and research institutions in France or abroad, or from public or private research centers.
L'archive ouverte pluridisciplinaire HAL, est destinée au dépôt et à la diffusion de documents scientifiques de niveau recherche, publiés ou non, émanant des établissements d'enseignement et de recherche français ou étrangers, des laboratoires publics ou privés.

\section{(c)(1)}

Distributed under a Creative Commons Attribution| 4.0 International License 


\title{
Wind turbine wake influence on the mixing of relative humidity quantified through wind tunnel experiments
}

\author{
Martín Obligado, ${ }^{1, a)}$ (D) Raúl Bayoán Cal, ${ }^{2, b)}$ (D) and Christophe Brun ${ }^{1, c)}$ \\ 'Univ. Grenoble Alpes, CNRS, Grenoble INP, LEGI, 38000 Grenoble, France \\ ${ }^{2}$ Department of Mechanical and Materials Engineering, Portland State University, Portland, Oregon 97201, USA
}

\author{
Note: This paper is part of the special issue on Wind Tunnel Research, Dynamics, and Scaling for Wind Energy. \\ a) Author to whom correspondence should be addressed: martin.obligado@univ-grenoble-alpes.fr

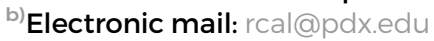 \\ ${ }^{c}$ Electronic mail: christophe.brun@univ-grenoble-alpes.fr
}

\begin{abstract}
An experimental study conducted in a wind tunnel on the mixing of moist air by a scaled wind turbine is presented. The experimental setup allows us to generate stable stratification conditions with respect to relative humidity and temperature in a closed-loop wind tunnel. The flow and its thermodynamic properties were characterized using a Cobra probe (a multi-hole pitot tube) and a sensor of local temperature and relative humidity, both used simultaneously to obtain vertical profiles. The flow and its stratification were measured downstream of a scaled rotor at two different streamwise distances ( 1 and 10 rotor diameters) and two Reynolds numbers based on the diameter of the wind turbine rotor (22 000 and 44000 , respectively). This was then compared to the inflow conditions. The wake mean structure and the humidity and temperature stratifications of the flow are found to be affected by the presence of the rotor. In particular, the stratification was always smaller one diameter downstream from the model (when compared to the empty test section case), and then was mostly recovered in the far wake (10 diameters downstream). This effect depended not only on the streamwise distance, but also on the Reynolds number of the flow. Finally, the bulk Richardson number $R_{b}$ was found to be an appropriate parameter to quantify this effect.
\end{abstract}

\section{INTRODUCTION}

Over the last few years, wind energy research has experienced an exponential growth worldwide. Consequently, it is an extremely active research field that involves specialists from many different domains. In particular, the study of the flow downstream of one (or several) turbines has captured the attention of the turbulence community as it is a complex problem that involves turbulent wakes, interactions between them and their coupling with the background turbulent flow. Measurements and numerical simulations have shown that the wake of wind turbines has an impact on the spatial development of the incoming flow as turbulent wakes enhance vertical mixing of momentum, heat, and moisture. Given the complexity of the flow, many numerical studies are performed using large eddy simulations, ${ }^{1-}$ although it is still possible to model this flow via Reynolds-AveragedNavier-Stokes models. ${ }^{4}$ Field measurements require advanced experimental techniques that allow us to quantify the wake properties for both neutral and stratified conditions. For instance, some studies have been performed with unmanned aerial systems, ${ }^{5}$ LIDARs $^{6,7}$ and a combination of power and meteorological measurements. ${ }^{8}$

In this context, climate change has also made spring freezes more usual, affecting crops worldwide, particularly vineyards and orchards. As expected, crops are strongly influenced by the climate and air properties. ${ }^{9,10}$ During these events, the moist air becomes strongly stratified in humidity and temperature, generating at the surface thermodynamic conditions that will eventually freeze and damage the crops. It is therefore relevant for all these applications to have a better understating of these stratified flows.

Previous experimental studies have shown that turbines are efficient for mixing moisture, but only on field conditions. In these works, measuring conditions are challenging and therefore there is a limited capability of acquiring data. For instance, the freestream background flow is heavily turbulent and unsteady. Studies on controlled wind 
tunnel conditions are therefore useful, as they open the possibility of isolating the contributions of different parameters, such as the freestream flow velocity and the role of the stratification, to name a few. Nevertheless, the study of these flows in wind tunnel conditions is extremely difficult. The main challenge is to achieve a stable humidity stratification while keeping a laminar incoming flow. On the one hand, humidity injection may add momentum to the flow, therefore producing a turbulent incoming flow. On the other hand, it is not evident how to generate a stable humidity stratification, as it will eventually saturate the air on the whole section. Performing scaled experiments on wind turbines and wind plants has been done to address fundamental questions around their interaction with the flow, power output maximization and/or controlling of the wakes to name a few, while some have touched on the subject of stratification. ${ }^{11-22}$ In these experiments, velocity and/or power measurements are usually the quantities of interest.

This study will focus on the technological means implemented to mitigate frost. We will study the interaction of a stratified inflow with the turbulent wake from a scaled wind turbine inside a wind tunnel. The incoming flow studied is a laminar flow with a stably stratified profile of humidity. While applications usually happen in situations with turbulent incoming flows, to generate such a flow with stratification in a wind tunnel is much more difficult than in the laminar case. In the wind tunnel, small turbulence intensities (below 2\%) can be reached far downstream a turbulence generator (grids, jets, wakes,...), but they all have a production range where intensities are very large and would thus break the stratification. Nevertheless, a laminar incoming flow presents some advantages: it allows us to isolate the coupling between the turbulent wake and the stratified incoming flows. The objective of the present work is then to quantify how the rotor enhances the mixing of the moist air, and if it eventually can, on some streamwise range, break the stratification and therefore avoid freezing. This strategy has the advantage that would allow the producers to avoid freezing while producing energy from a clean source.

In this work, an innovative experimental setup is proposed, where humidifiers are located on the convergence section of a lowturbulence closed-loop wind tunnel that is operated continuously. This allows us to generate a stably stratified humidity profile while keeping the flow laminar. A scaled rotor is then installed and local measurements of humidity, temperature, and velocity are performed at different vertical profiles for different streamwise locations. The presence of a humidity stratification is found to modify the structure of the turbulent wake. Furthermore, the turbine significantly enhances mixing in the near wake. This study therefore shows the viability of the study of mixing of different stratified scalars under controlled wind tunnel conditions.

\section{EXPERIMENTAL SETUP}

Experiments were conducted in the Lespinard wind tunnel at Laboratoire des Écoulements Géophysiques et Industriels (LEGI), Université Grenoble Alpes (Grenoble, France). This closed-loop tunnel has a $4 \mathrm{~m}$ long test section, with cross-sectional dimensions of $0.75 \mathrm{~m} \times 0.75 \mathrm{~m}$. Upstream of the test section, there is a convergence section. This last section is also squared, with a surface contraction coefficient of 12 . The resulting dimensions of the whole equipment are $16.03 \mathrm{~m}$ in length, $5.05 \mathrm{~m}$ in height, and $2.60 \mathrm{~m}$ in width. For all the operating conditions studied here, the turbulence intensity of the flow (without any model added) stays below $0.2 \%$.

Three humidifiers are placed upstream the convergence section to generate moisture (see Fig. 1). They are commercial humidifiers Taotronics TT-AH001 operated at a flow rate of $300 \mathrm{ml} / \mathrm{h}$ using tap water. The humidifiers have a capacity of $4 \mathrm{l}$ each and can operate continuously for several hours. As they are located at the floor of the convergence section and operated continuously, they generate a stable, stratified, and stationary humidity layer. To achieve a stable stratification, the wind tunnel is set to the required velocity with the humidifiers activated at least $1 \mathrm{~h}$ before the measurements are taken to allow for equilibrium within the loop. A part of the moist mass of air that goes through the test section will already mix due to the turbulence on the outer layer of the boundary layer (and the turbulent wake when the model is present). As the wind tunnel is a vertical closed-loop, the remaining moisture from the layer, due to its higher density and lower velocity, will not be transported to the upper part of the tunnel. The wind tunnel is nevertheless not isolated from the room (it has some holes and exchangers outside the test section), and therefore the properties of the stratified flow depend on the room conditions, when

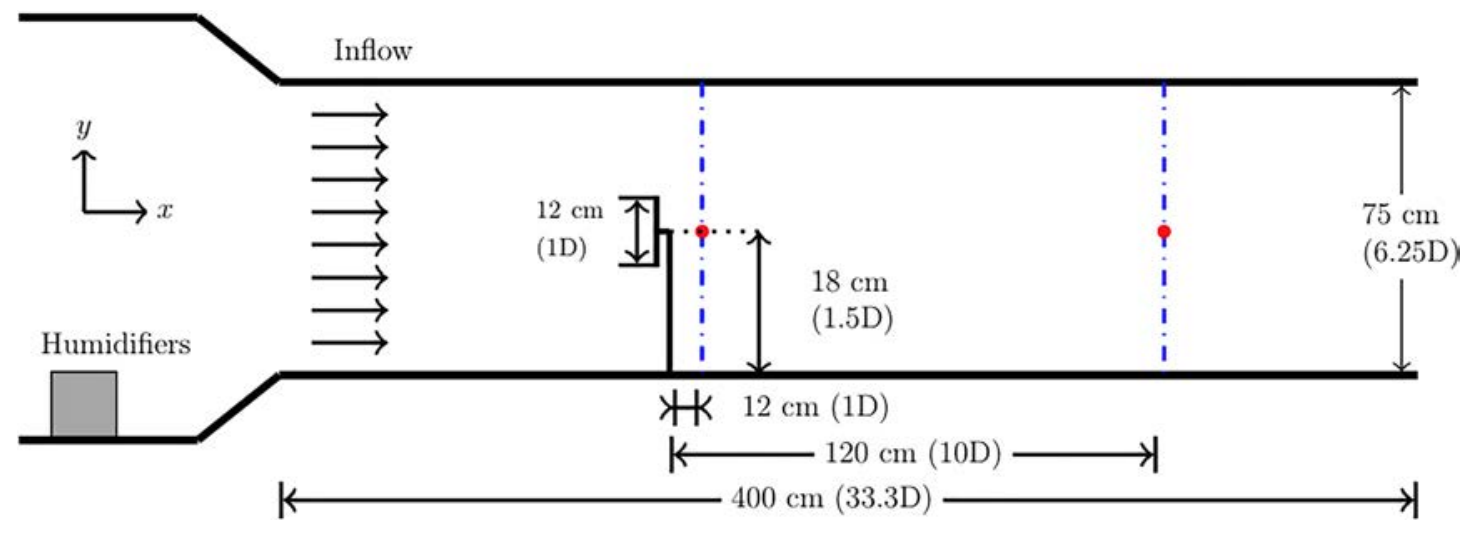

FIG. 1. Schematic of the experimental setup (not at scale). Three humidifiers (aligned on the $z$ direction) are placed on the flow of the convergence section. Then, a Cobra probe and a humidity/temperature sensor are place on a traverse system, also aligned in the $z$ direction and at the same distance from the centerline of the rotor. A second humidity/temperature sensor is located downstream, at the end of the test section (not shown in the figure). 
eventually a steady state is obtained. After we start the wind tunnel with the humidifiers, the mass of air within the tunnel increases in relative humidity globally until equilibrium is achieved, and we did not observe that the stratified layer increased over time, consistently with these assumptions.

The model used for this work is a three-blade, horizontal axis turbine. The setup is similar to a previous experiment performed on the same facility. ${ }^{23}$ The rotor is based on the design of Odemark and Fransson, employing a Blade Element Momentum scheme with Glauert optimization. ${ }^{24,25}$ Rotor blade pitch is set at $6.5^{\circ}$ to agree with Odemark and Fransson and the rotor diameter was $D=12 \mathrm{~cm}$. This represents an experimental scaling of 0.001:1 compared to full-scale turbines. $^{26,27}$ The nacelle of the turbine is placed $50 \mathrm{~cm}$ downstream the inlet of the test section (or 4.17D) at $18 \mathrm{~cm}$ (or 1.5D) height and at the center on the spanwise direction. The mast used is a $1.27 \mathrm{~cm}$ diameter circular cylinder.

Three-dimensional (3D) velocity time signals are recorded using a Cobra probe manufactured by $\mathrm{TFI},{ }^{28}$ which is able to compute the three fluctuating velocities $\left(u^{\prime}, v^{\prime}, w^{\prime}\right)$ plus their mean $(U, V, W)$ and rms $(u, v, w)$, where $u$ actually corresponds to the standard deviation of $u^{\prime}$ values, with a temporal resolution of $1250 \mathrm{~Hz}$. The acquisition time is set to $60 \mathrm{~s}$ at the maximum sampling frequency. We remark that the probe has a $4 \mathrm{~mm}^{2}$ sensitive area, and therefore cannot resolve the small scales of the turbulent flow.

Humidity is measured with a probe from Campbell Scientific, Inc. (model CS215) at a sampling rate of $0.5 \mathrm{~Hz}$. It measures both the relative humidity of the air (with a relative precision of $\pm 2 \%$ ) and its temperature $\left( \pm 0.4{ }^{\circ} \mathrm{C}\right)$. Two of these humidity sensors are placed in the wind tunnel: one at the same streamwise position as the Cobra probe [that measures the relative humidity $h_{i}$ and absolute temperature $T(y)$ ], as detailed below, and another one near the floor (at constant height $y=1.5 \mathrm{~cm}$ ) at the outlet of the test $\mathrm{sec}$ tion (measuring in this case the relative humidity $h_{0}$ and absolute temperature $T_{0}$ at that height). The second sensor can then be used as a reference of humidity and temperature far downstream of the wake. The position corresponds to more than 30 diameters downstream of the rotor.

Vertical profiles are measured at $x / D=1$ and $x / D=10$, with $x$ the distance between the probe and the end of the rotor. Two different incoming velocities are tested: $U_{\infty}=2.7$ and $5.5 \mathrm{~m} / \mathrm{s}$, that correspond to Reynolds numbers, based on the diameter of the rotor, $R e_{D}$, of 22000 and 44000 , respectively. For each $U_{\infty}$ and $x$-position, a vertical profile is performed between $y=1 \mathrm{~cm}$ and $y=44.6 \mathrm{~cm}$ that comprised at least 14 and up to 22 points. The spacing is not uniform, so a better resolution could be obtained near the floor of the wind tunnel and the centerline of the rotor. The Cobra probe and the humidity sensor are used simultaneously during each profile. They are both placed at the same vertical position $y$, symmetrically placed off-center at $5 \mathrm{~cm}$ each (or $\mathrm{D}=0.42$ ). Table I shows relevant parameters for the two Reynolds numbers explored. The accuracy of velocity measurements is of $0.2 \mathrm{~m} / \mathrm{s}$ and of 2 and $5 \mathrm{~mm}$ for the $y$ and $x$ positions, respectively. Considering the time required to activate the humidifiers that required to physically access the convergent section and achieving a stable and steady stratification, two profiles per day are measured on average. Significant variations are not found in the averaged and rms velocity profiles for the dry case when humidifiers are placed or not on the convergence section [see Figs. 2(c) and 2(d)]. Nevertheless, this
TABLE I. Experimental parameters at $x / D=10$ for the empty test section and both cases studied. $R e_{D}$ corresponds to the Reynolds number based on the disk diameter, $R e_{D}=U_{\infty} D / \nu$ (with $\nu$ the kinematic viscosity of air). The freestream velocity $U_{\infty}$ was estimated from the highest point of the profile (around $45 \mathrm{~cm}$ ) above the floor. The freestream turbulence intensity $u_{\infty} / U_{\infty}$ was estimated at the same location.

\begin{tabular}{lccc}
\hline Case & $R e_{D}$ & $U_{\infty}(m / s)$ & $u_{\infty} / U_{\infty}$ \\
\hline 1 & 22000 & 2.73 & 0.0050 \\
2 & 44000 & 5.46 & 0.0025 \\
\hline
\end{tabular}

could be caused by the moderate resolution from the Cobra on velocity and our uncertainty in vertical displacements.

Figures 2(a) and 2(b) show the profiles of temperature and relative humidity with and without the humidifiers for the empty wind tunnel. They were obtained at $x=1.20 \mathrm{~m}$ that corresponds to $x / D$ $=10$ when the model is present. We can see to which extent the thermodynamic properties of air are constant when humidifiers are not operated. When they are active, a humidity profile in $y$ is observed that also involves a variation in temperature. The first humidity and temperature sensor, located upstream moves vertically with the cobra probe, and hence the relative humidity $h_{i}$ and velocity time series are registered at the same values of $y$. As detailed above, the second one is located far downstream and not at the same streamwise position as the other so it does not perturb the boundary layer nor the stratification. It is placed at a constant height $(y=1.5 \mathrm{~cm})$ and therefore can also be used to quantify the steadiness of the stratification, as the values of $h_{0}$ and $T_{0}$ should be constant at that location [Figs. 2(a) and 2(b) show this is approximately verified]. To cater for variations of ambient temperature and relative humidity between different days of the experimental campaign, in the results section, the humidity stratification via the ratio $h_{i} / h_{0}$ is quantified.

Figure 2 shows that the stratification remains significant up to $y \sim 25 \mathrm{~cm}$, and therefore the bottom and top tip from the rotor lay within it. It also expands far beyond the boundary layer, that has a thickness of around $5 \mathrm{~cm}$, at $x=10 D$, as shown in Figs. 2(c) and 2(d). It can also be observed that both temperature and humidity are not linearly stratified, but rather present a jump. While these conditions present some differences from the atmospheric turbulent boundary layer, they do represent other realistic flows, such as de katabatic boundary layer. ${ }^{29}$

We also quantified the virtual temperature of the fluid that accounts for changes in humidity following an isentropic process. It is defined as

$$
T_{v}=T(1+0.61 r),
$$

where $r$ corresponds to $r=\varepsilon e /\left(P_{0}-e\right)$ and $T$ to the absolute temperature [as shown in Fig. 2(b)]. $P_{0}$ is the absolute pressure in the wind tunnel, $\varepsilon=0.622$ is the ratio of gas constants for dry air to that for water vapor, and $e$ is the partial pressure of the vapor. It is defined as $e=e_{s} H R / 100$, where $H R$ stands for the relative humidity, and is equal to $h_{i}$ in our case. $e_{s}$ is the saturation pressure, deduced via the Clausius-Clapeyron equation,

$$
e_{s}=e_{0} e^{\left(L / R_{v}\right)\left(1 / T_{0}-1 / T\right)}
$$

$L$ is the latent heat of vaporization $(L=2500 \mathrm{~kJ} / \mathrm{kg}$ for water), $e_{0}=611 \mathrm{~Pa}$ is the saturation pressure at $T_{0}=273.15 \mathrm{~K}$, and finally $R_{v}=461 \mathrm{~J} \mathrm{~kg}^{-1} \mathrm{~K}^{-1}$ is the ideal gas constant for water vapor. 

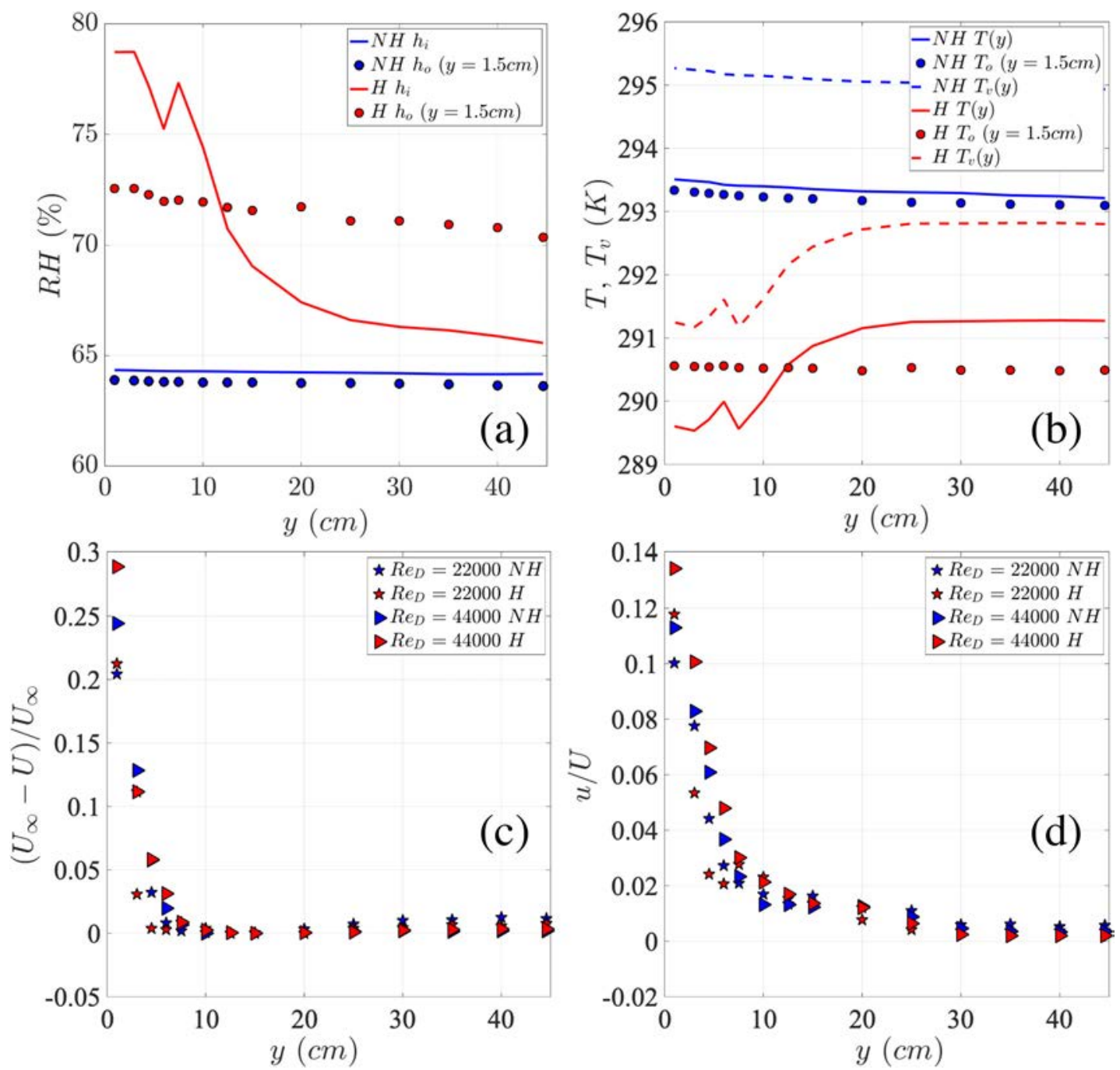

FIG. 2. Vertical evolution of air relative humidity $(R H)$ for different cases (a). Vertical evolution of the absolute $(T)$ and virtual $\left(T_{v}\right)$ temperatures for the same cases (b). Red symbols correspond to the humidifiers activated (labelled as $H$ in figure's legend) and blue to when they are deactivated (respectively, $\mathrm{NH}$ ). In both figures, circles correspond to the measurements taken by the second humidity sensor $\left(h_{0}\right)$ placed at the exit of the test section and at fixed height of $y=1.5 \mathrm{~cm}$. In all cases results correspond to $R e_{D}=44000 . h_{0}$ and $T_{0}$ correspond to values takes by the probe at the outlet of the test section while $h_{i}$ and $T_{i}$ to the one placed in the traverse system. Local velocity deficit $\left(U_{\infty}-U\right) / U_{\infty}$ (c) and turbulence intensity $u / U$ (d) for both values of $R e_{D}$ studied.

Profiles of $T_{v}$ without the rotor are shown in Fig. 2(b). We see that the virtual temperature follows an opposite trend than the relative humidity, but shows a similar stratification. In fact, the increasing trend observed on $T_{v}$ is due to the increase in absolute temperature with height. The contribution of $H R$ to the variation of $T_{v}$ is around $20 \%$ the contribution of the temperature, and on the opposite direction (for the increasing value of $y$, humidity decreases while temperature increases, modifying $T_{v}$ accordingly). In Sec. III, we will show this parameter can be used to quantify the stratification.

To check that the profiles are stationary and in equilibrium (stable in time), Fig. 3 contains signals of the relative humidity as a function of time for both sensors at $y=44.6 \mathrm{~cm}$ (or $y / D=3.72$ ) and $7.5 \mathrm{~cm}$ (or $y / D=0.63$ ) at the highest Reynolds tested. All profiles are relatively stationary in time, despite the presence or not of the humidity stratification.

\section{RESULTS}

Figure 4 contains results at the highest tested velocity, $R e_{D}=44000$. Figure 4(a) provides the vertical profiles of $h_{i} / h_{o}$, the $H R$ at the probe in the traverse with respect to the one placed in the outlet of the section. Results are presented in this way as the absolute values of the $H R$ may change for measurements performed on different days. In all cases, an evident stratification in humidity and virtual temperature is observed [Fig. 4(b)]. We do not report results at $x / D=1$ below $10 \mathrm{~cm}(y / D \sim 0.83)$ because on that range the air was saturated in humidity and air condensed 

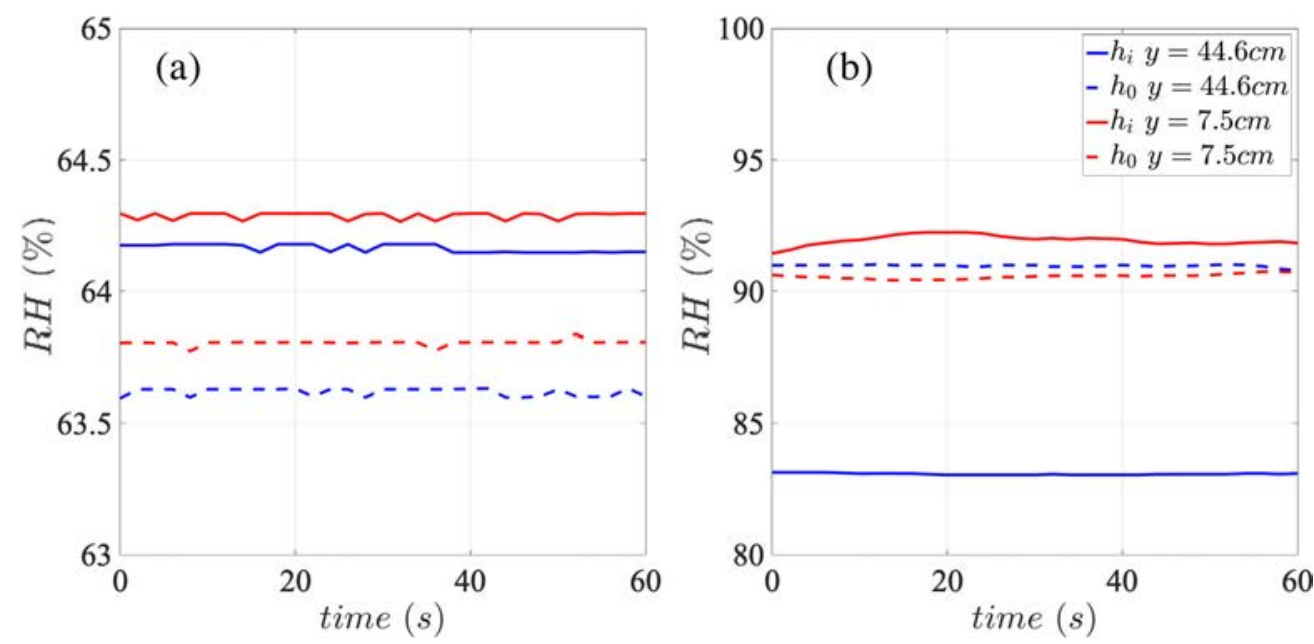

FIG. 3. Temporal evolution of the relative humidity for air without (a) and with (b) the humidifiers activated. Results correspond to $R e_{D}=44000$.

on the probes. Therefore, within this range, a plateau was already reached for $h_{i} / h_{0}$ and $T_{v}$, as both temperature and relative humidity remain constant. At this $R e_{D}$, the stratification is always present when humidifiers are in operation. The stratification at $x / D=1$ and $x / D=10$ is found to be qualitatively different when compared to the empty test section.
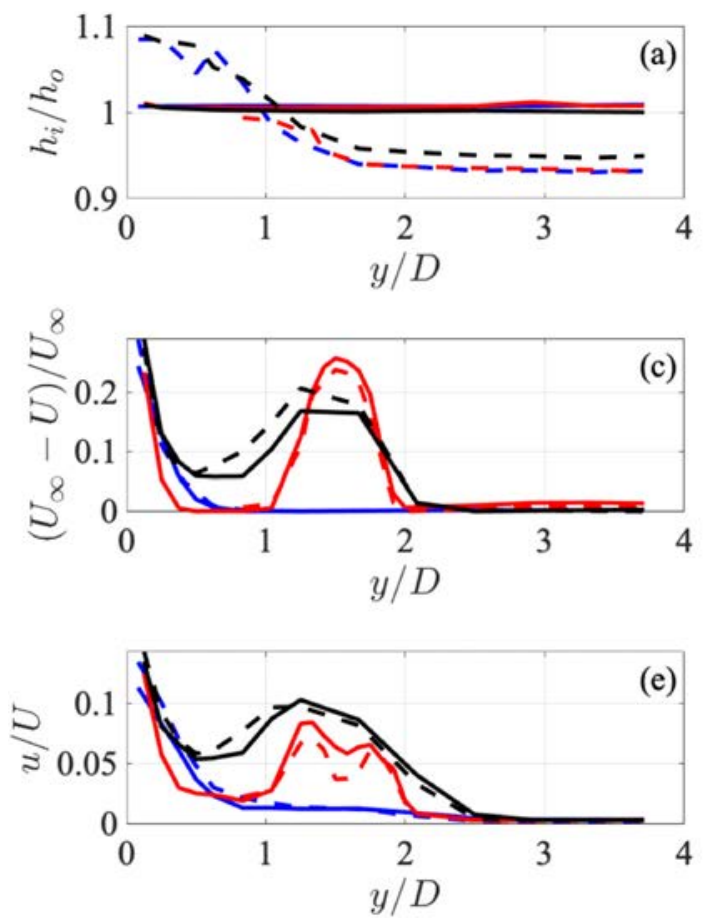

Figure 4 (c) shows the normalized velocity deficit $\left(U_{\infty}-U\right) / U_{\infty}$. We can see the structure of the wake when the model is present, and in all cases the presence of the boundary layer (it is remarked that the measurements with no model have been done at the same streamwise position that corresponds to $x / D=10$ ). Typical turbulent near and far wake characteristics are observed for the
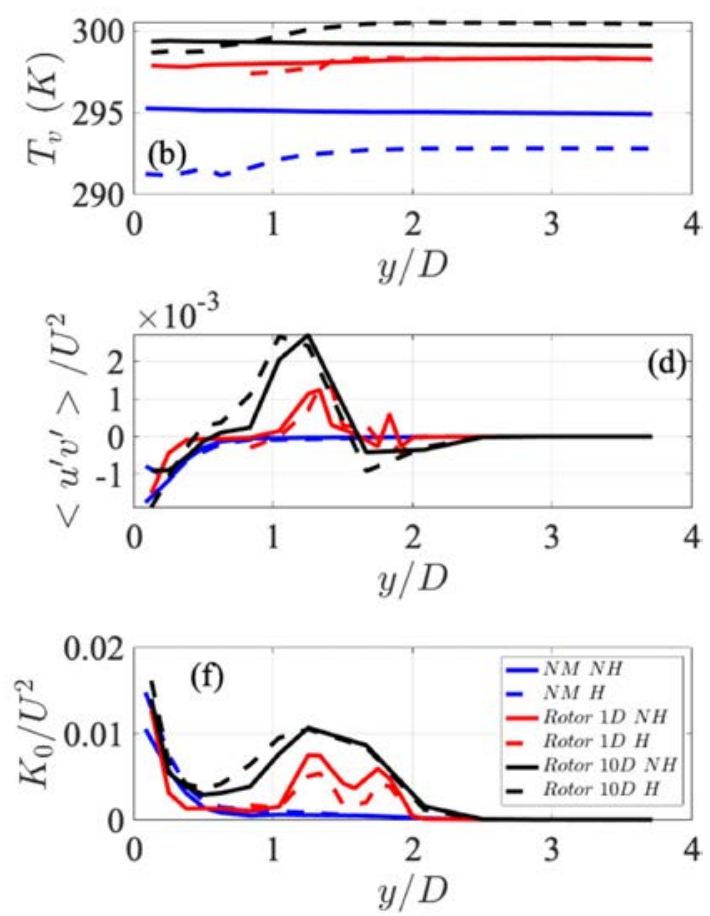

FIG. 4. Results obtained at $R e_{D}=44000$. Ratio of relative humidity $h_{i} / h_{0}$ (a), relative temperature $T_{r}\left(\right.$ b), local velocity deficit $\left(U_{\infty}-U\right) / U_{\infty}$ (c) and normalized Reynolds stresses, turbulence intensity and kinetic energy [(d)-(f), respectively]. In all cases, solid lines correspond to the humidifiers deactivated and the dashed ones to the opposite situation. Blue lines correspond to an empty test section (no model), and red and black to vertical profiles at $x=1 D$ and $x=10 D$, respectively. 

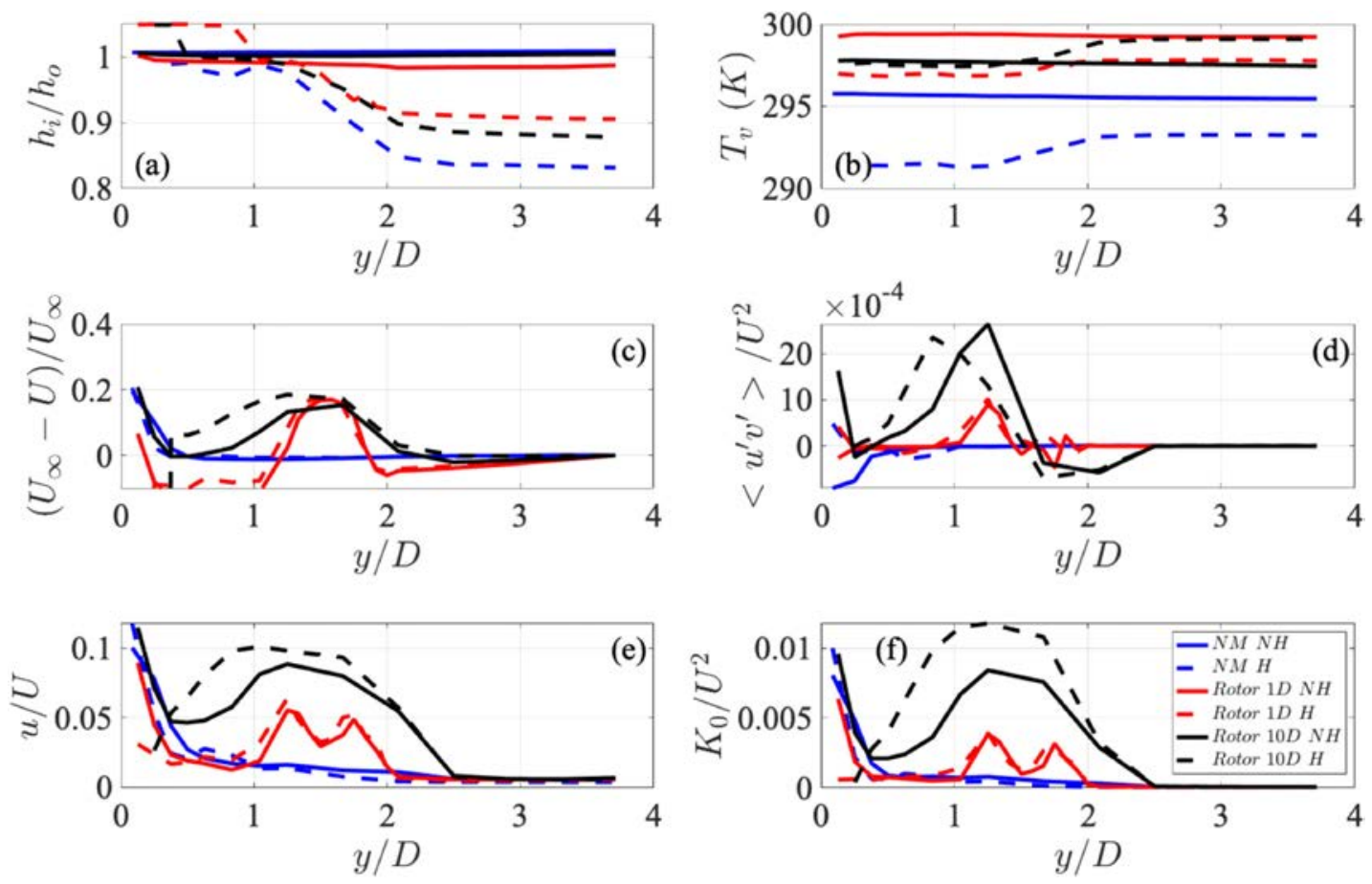

FIG. 5. Same as Fig. 4, but for results obtained at $R e_{D}=22000$.

Reynolds stresses [Fig. 4(d)] and the local turbulence intensity [Fig. 4(e)]. As the Cobra probe also resolves the full velocity vector, values for the full kinetic energy $K_{0}=\frac{1}{2}\left(u^{2}+v^{2}+w^{2}\right)$ are reported [Fig. 4(f)]. The measurements of the mean and rms velocity for the non-stratified case are consistent with those reported by Smith et al. ${ }^{23}$ for tracer particles.

Interestingly, an effect in terms of the mean wake structure is also found. Particularly at $x / D=1$, the turbulence intensity and normalized kinetic energy are smaller when a humidity stratification is present. For instance, at the centerline these parameters are 36\% and 53\% smaller, respectively. Also, a smaller effect of $8 \%$ is observed for the velocity deficit. Furthermore, this effect seems to disappear in the far wake, at $x / D=10$. For the latter distance, some differences are also appreciated, yet the interaction with the boundary layer developed at the floor of the wind tunnel does not allow us to draw further conclusions.
Figure 5 shows the same analysis but for the lower Reynolds number of $R e_{D}=22000$. A stratification in humidity and virtual temperature remains. Nevertheless, in this case, the trends observed in the shape of the mean wake are inverted, as the presence of humidity seems to increase the velocity deficit, turbulence intensity and normalized energy of the wake. While in Figs. 5 as well as Figs. 4(d)-4(f), results normalized by the local mean velocity $U$ are reported, when normalizing with $U_{\infty}$, the trends remain unchanged.

The stratification can be then quantified in terms of the virtual temperature via the Brünt-Väisäla frequency, ${ }^{30}$ defined as

$$
N_{r e f}=\sqrt{\frac{g}{T_{0}} \frac{\partial T_{v}(y)}{\partial y}},
$$

with $g$ being the acceleration of gravity. Table II shows the values of $N_{r e f}$ for all conditions studied. It is confirmed that the flow has a strong

TABLE II. Brünt-Väisäla frequency and bulk Richardson numbers estimated for all cases studied. The virtual temperature variation between $y=3 D$ and $y=0$ is also shown for reference.

\begin{tabular}{lcccccc}
\hline Case & $R e_{D}$ & Rotor (yes/no $)$ & $\mathrm{x} / \mathrm{D}$ & $N_{\text {ref }}(\mathrm{Hz})$ & $T_{v}(y=3 D)-T_{v}(y=0)(\mathrm{K})$ \\
\hline 1 & 22000 & No & 10 & 0.43 & 1.89 & 0.90 \\
2 & 22000 & Yes & 1 & 0.30 & 1.60 & 0.044 \\
3 & 22000 & Yes & 10 & 0.40 & 1.61 & 0.096 \\
4 & 44000 & No & 10 & 0.40 & 0.90 & $1.5 \times 10^{4}$ \\
5 & 44000 & Yes & 1 & 0.30 & 1.51 & 0.0021 \\
6 & 44000 & Yes & 10 & 0.39 & 0027 \\
\hline
\end{tabular}


stratification, with a value of $N_{r e f} \sim 0.4 \mathrm{~Hz}$ for an empty test section and subsequently the rotor mixes efficiently the moisture at $x / D=1$. At $x / D=10$, the effect is much smaller, vanishing at the largest Reynolds studied.

The stratification is quantified via the Bulk Richardson number. It is defined as ${ }^{31}$

$$
R_{b}=\frac{g \Delta T_{v} \Delta y}{\left\langle T_{v}\right\rangle(\Delta U)^{2}},
$$

where $\Delta T, \Delta y$ and $\Delta U$ are defined as the increments between $y / D$ $=1.5$ (that correspond approximately to the maximum velocity deficit) and $y / D=3$ (that is always outside the wake). $\left\langle T_{v}\right\rangle$ is then the mean temperature in the range $1.5<y / D<3$. Using this parameter, the stratification that arises from the wake shear profile is therefore quantified, taking into consideration the temperature variations. Results are also shown in Table II. As expected, when no model is present, large values of $R_{b}$ are observed which should tend to infinity if the flow was fully homogeneous in the wind tunnel section. Small values of $R_{b}<1$ are obtained when the rotor is present, showing the presence of a regime where buoyancy is relevant in the flow. Furthermore, once more we appreciate differences with $R e_{D}$, as the bulk Richardson number is one order of magnitude larger with respect to the largest value of $R e_{D}$. For all cases, when the rotor is present, $R_{b}$ is below the critical value of $R_{b c}=0.2 .^{32,33}$ Above this value, turbulence may develop and maintain against stabilization through stratification effects.

\section{CONCLUSIONS}

The main objective of this work is to present a new experimental setup that allows us to obtain a stable humidity stratification in a wind tunnel. Here, a strategy that involves placing a series of humidifiers on the wall of the convergent section of a wind tunnel allows us to generate such stratification, while keeping the flow laminar (for an empty test section).

It is demonstrated how this experimental setup can be applied to a relevant problem for the environment; the mixing of moist air by a wind turbine. In the near wake, one diameter downstream, mixing is significantly enhanced and the stratification is less important. Furthermore, the structure of the mean turbulent wake is also significantly modified. These results show an important dependency on the Reynolds number $R e_{D}$.

Finally, the bulk Richardson number $R_{b}$ is found to be an appropriate parameter to quantify this effect. Below a critical value of around $R_{b c}=0.2$, the effect of virtual temperature stratification tends to deflect the mean wake downwards, toward the floor. A similar deformation is observed for the turbulent kinetic profile, contrary to what would be expected for a stably stratified boundary layer for a regime characterized with a Brünt-Vaisälä frequency of about $N=0.4 \mathrm{~Hz}$.

Despite the interest in the results presented, this work remains a first approach to the problem and further research is needed to explore the utility of this new experimental configuration. For instance, a study that includes profiles at more values of $R e_{D}$ and $x / D$ could shed some light on the evolution of the humidity profile. It is of particular interest how results will vary for larger values of $R e_{D}$, closer to those found in applications. The tip speed ratio of the rotor used in this work and the size of the tunnel limited the values of $R e_{D}$ explored in the experiments. Furthermore, while only using three humidifiers, it is possible to use a larger number, and get a better control of properties of the stratification profile in the wind tunnel.

\section{DATA AVAILABILITY}

The data that support the findings of this study are available from the corresponding author upon reasonable request.

\section{REFERENCES}

${ }^{1}$ J. Meyers and C. Meneveau, "Large eddy simulations of large wind-turbine arrays in the atmospheric boundary layer," in 48th AIAA Aerospace Sciences Meeting Including the New Horizons Forum and Aerospace Exposition (2010), p. 827.

${ }^{2}$ R. Stoll and F. Porté-Agel, "Surface heterogeneity effects on regional-scale fluxes in stable boundary layers: Surface temperature transitions," J. Atmos. Sci. 66, 412-431 (2009).

${ }^{3}$ M. Calaf, M. B. Parlange, and C. Meneveau, "Large eddy simulation study of scalar transport in fully developed wind-turbine array boundary layers," Phys. Fluids 23, 126603 (2011).

${ }^{4}$ W. Yue, Y. Xue, and Y. Liu, "High humidity aerodynamic effects study on offshore wind turbine airfoil/blade performance through CFD analysis," Int. J. Rotating Mach. 2017, 1.

${ }^{5} \mathrm{~K}$. A. Adkins and A. Sescu, "Observations of relative humidity in the nearwake of a wind turbine using an instrumented unmanned aerial system," Int. J. Green Energy 14, 845-860 (2017).

${ }^{6}$ L. Zhan, S. Letizia, and G. V. Iungo, "Optimal tuning of engineering wake models through LIDAR measurements," Wind Energy Sci. 5, 1601-1622 (2020).

${ }^{7}$ G. Lungo and F. Porte-Agel, "Volumetric scanning of wind turbine wakes under convective and neutral stability regimes," J. Atmos. Oceanic Technol. 31, 2035-2048 (2014).

${ }^{8}$ K. S. Hansen, R. J. Barthelmie, L. E. Jensen, and A. Sommer, "The impact of turbulence intensity and atmospheric stability on power deficits due to wind turbine wakes at horns rev wind farm," Wind Energy 15, 183-196 (2012).

${ }^{9}$ D. Mortley, C. Bonsi, P. Loretan, W. Hill, and C. Morris, "Relative humidity influences yield, edible biomass, and linear growth rate of sweetpotato," HortScience 29, 609-610 (1994).

${ }^{10} \mathrm{~K}$. Everard, H. Oldroyd, and A. Christen, "Turbulent heat and momentum exchange in nocturnal drainage flow through a sloped vineyard," BoundaryLayer Meteorol. 175, 1-23 (2020).

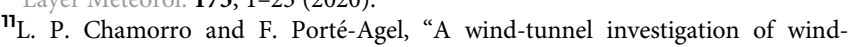
turbine wakes: Boundary-layer turbulence effects," Boundary-Layer Meteorol. 132, 129-149 (2009).

${ }^{12}$ R. Scott, B. Viggiano, T. Dib, N. Ali, M. Hölling, J. Peinke, and R. B. Cal, "Wind turbine partial wake merging description and quantification," Wind Energy 23, 1610-1618 (2020).

${ }^{13}$ S. Rockel, J. Peinke, M. Hölling, and R. B. Cal, "Dynamic wake development of a floating wind turbine in free pitch motion subjected to turbulent inflow generated with an active grid," Renewable Energy 112, 1-16 (2017).

${ }^{14}$ S. Rockel, E. Camp, J. Schmidt, J. Peinke, R. B. Cal, and M. Hölling, "Experimental study on influence of pitch motion on the wake of a floating wind turbine model," Energies 7, 1954-1985 (2014).

${ }^{15}$ N. Hamilton, H.-S. Kang, C. Meneveau, and R. B. Cal, "Statistical analysis of kinetic energy entrainment in a model wind turbine array boundary layer," J. Renewable Sustainable Energy 4, 063105 (2012).

${ }^{16} \mathrm{G}$. V. Iungo, "Experimental characterization of wind turbine wakes: Wind tunnel tests and wind LIDAR measurements," J. Wind Eng. Ind. Aerodyn. 149, 35-39 (2016).

${ }^{17} \mathrm{M}$. Bastankhah and F. Porté-Agel, "Wind tunnel study of the wind turbine interaction with a boundary-layer flow: Upwind region, turbine performance, and wake region," Phys. Fluids 29, 065105 (2017).

${ }^{18}$ B. Dou, M. Guala, L. Lei, and P. Zeng, "Experimental investigation of the performance and wake effect of a small-scale wind turbine in a wind tunnel," Energy 166, 819-833 (2019). 
${ }^{19}$ J. Bartl, F. Mühle, J. Schottler, L. Saetran, J. Peinke, M. Adaramola, and M. Hölling, "Wind tunnel experiments on wind turbine wakes in yaw: Effects of inflow turbulence and shear," Wind Energy Science 3, 329-343 (2018).

${ }^{20}$ P. E. Hancock and F. Pascheke, "Wind-tunnel simulation of the wake of a large wind turbine in a stable boundary layer: Part 2, the wake flow," BoundaryLayer Meteorol. 151, 23-37 (2014).

${ }^{21}$ F. Campagnolo, V. Petrović, J. Schreiber, E. M. Nanos, A. Croce, and C. L. Bottasso, "Wind tunnel testing of a closed-loop wake deflection controller for wind farm power maximization," J. Phys.: Conf. Ser. 753, 032006 (2016).

${ }^{22}$ R. B. Cal, J. Lebrón, L. Castillo, H. S. Kang, and C. Meneveau, "Experimental study of the horizontally averaged flow structure in a model wind-turbine array boundary layer," J. Renewable Sustainable Energy 2, 013106 (2010).

${ }^{23}$ S. E. Smith, K. N. Travis, H. Djeridi, M. Obligado, and R. B. Cal, "Dynamic effects of inertial particles on the wake recovery of a model wind turbine," Renewable Energy 164, 346-361 (2021).

${ }^{24}$ Y. Odemark and J. H. Fransson, "The stability and development of tip and root vortices behind a model wind turbine," Exp. Fluids 54, 1591 (2013).

${ }^{25}$ J. Schottler, A. Hölling, J. Peinke, and M. Hölling, "Design and implementation of a controllable model wind turbine for experimental studies," J. Phys.: Conf. Ser. 753, 072030 (2016).
${ }^{26}$ L. P. Chamorro and F. Porte-Agel, "Turbulent flow inside and above a wind farm: A wind-tunnel study," Energies 4, 1916-1936 (2011).

${ }^{27} \mathrm{~N}$. Hamilton, M. Melius, and R. B. Cal, "Wind turbine boundary layer arrays for Cartesian and staggered configurations-Part I: Flow field and power measurements," Wind Energy 18, 277-295 (2015).

${ }^{28}$ S. Watkins, P. Mousley, and J. Hooper, "Measurement of fluctuating flows using multi-hole probes," in Ninth International Congress on Sound and Vibration (2002), pp. 8-11.

${ }^{29}$ C. Brun, S. Blein, and J.-P. Chollet, "Large-eddy simulation of a katabatic jet along a convexly curved slope. Part II: Statistical results," J. Atmos. Sci. 74, 4047-4073 (2017).

${ }^{30} \mathrm{R}$. B. Stull, An Introduction to Boundary Layer Meteorology (Springer Science \& Business Media, 2012), Vol. 13.

${ }^{31}$ C. M. St Martin, J. K. Lundquist, A. Clifton, G. S. Poulos, and S. J. Schreck, "Wind turbine power production and annual energy production depend on atmospheric stability and turbulence," Wind Energy Sci. 1, 221-236 (2016).

${ }^{32}$ J. Kondo, O. Kanechika, and N. Yasuda, "Heat and momentum transfers under strong stability in the atmospheric surface layer," J. Atmos. Sci. 35, 1012-1021 (1978).

${ }^{33}$ F. Nieuwstadt and J. Meeder, "Les of air pollution dispersion: A review," in New Tools in Turbulence Modelling (Springer, Berlin, 1996), pp. 265-280. 